\title{
A Newly Reported Species of Genus Pseudoneoponera Donisthorpe, 1943 (Formicidae: Ponerinae) from Azad Jammu and Kashmir, Pakistan
}

\author{
Najeeb Ullah ${ }^{1 *}$, Adnan Ihsan ${ }^{1}$, Syed Fahad Shah ${ }^{1}$, Kamran Sohail ${ }^{1}$, Muhammad Sohail Khan ${ }^{1}$ and Said \\ Hussain Shah ${ }^{2}$
}

${ }^{1}$ Department of Entomology, The University of Agriculture, Peshawar, Pakistan, 25100 Pakistan; ${ }^{2}$ Insect pest Management Program, Institute of Plant and Environmental Protection, National Agriculture Research Centre, Islamabad, Pakistan.

Abstract | Pakistan has diverse ant biodiversity but very little work is done on this group. Based on the recent collected specimens of Formicidae from Kahuta Azad Kashmir Pakistan Pseudoneoponera rufipes Jerdon, 1851 is reported for the first time from part of region. Morphological descriptions and digital images are provided.

Received | December 14, 2021; Accepted | January 31, 2022; Published | February 12, 2022

*Correspondence | Najeeb Ullah, Department of Entomology, The University of Agriculture, Peshawar-Pakistan, 25100 Pakistan; Email: najeebkifayat53@gmail.com

Citation | Ullah, N., A. Ihsan, S.F. Shah, M.S. Khan and S.H. Shah. 2022. A newly reported species of genus Pseudoneoponera Donisthorpe, 1943

(Formicidae: Ponerinae) from Azad Jammu and Kashmir, Pakistan. Pakistan Journal of Agricultural Research, 35(1): 47-51.

DOI | https://dx.doi.org/10.17582/journal.pjar/2022/35.1.47.51

Keywords | Taxonomy, Ponerinae, Morphology, Rufipes, New Record, Azad Jammu and Kashmir, Distribution

\section{Introduction}

A nts are eusocial insects that belong to family Formicidae of the order Hymenoptera. They are said to be present on earth about 120 million years ago (Ward, 2007). They are one of the most diverse and pervasive group of the social insect within order Hymenoptera (Bolton, 2011). Ants are further classified into 26 subfamilies with about 16,318 described species in 482 genera (Bolton, 2021). There are 103 ant species in 35 genera and 7 subfamilies reported from Pakistan (Rasheed et al., 2019).

Pseudoneoponera Donisthorpe, 1943 is a moderately large genus with 18 described species widely distributed from India to Australia. Genus Pseudoneoponera is well known for their unusual foamy secretions exuded from the stings of workers for its small colonies and usual social systems including the frequent occurrence gamergates (Schmidt and Shattuck, 2014).

In current study one species of this genus represent- ing the first report from Azad Kashmir, Pakistan with descriptions of morphological characters.

\section{Materials and Methods}

Ant's specimens were collected from Kahuta, Azad Kashmir, Pakistan during May, 2020. Collected specimens were observed under the stereo microscope Nikon SMZ 745T and pictures were captured with Nikon DS-Fi2 digital camera attached to the microscope. Terminologies of Hollodobler and Wilson (1990) were followed for morphological descriptions (Figure 1).

\section{Measuremetns and indices}

Measurements follow the standard and are in millimeters $(\mathrm{mm})$

\section{Measurements}

$\mathrm{TL}=$ Total length: $\mathrm{HL}+\mathrm{WL}+\mathrm{GL}$.

EL=Length of Eye; maximum diameter of eye in lateral view. 


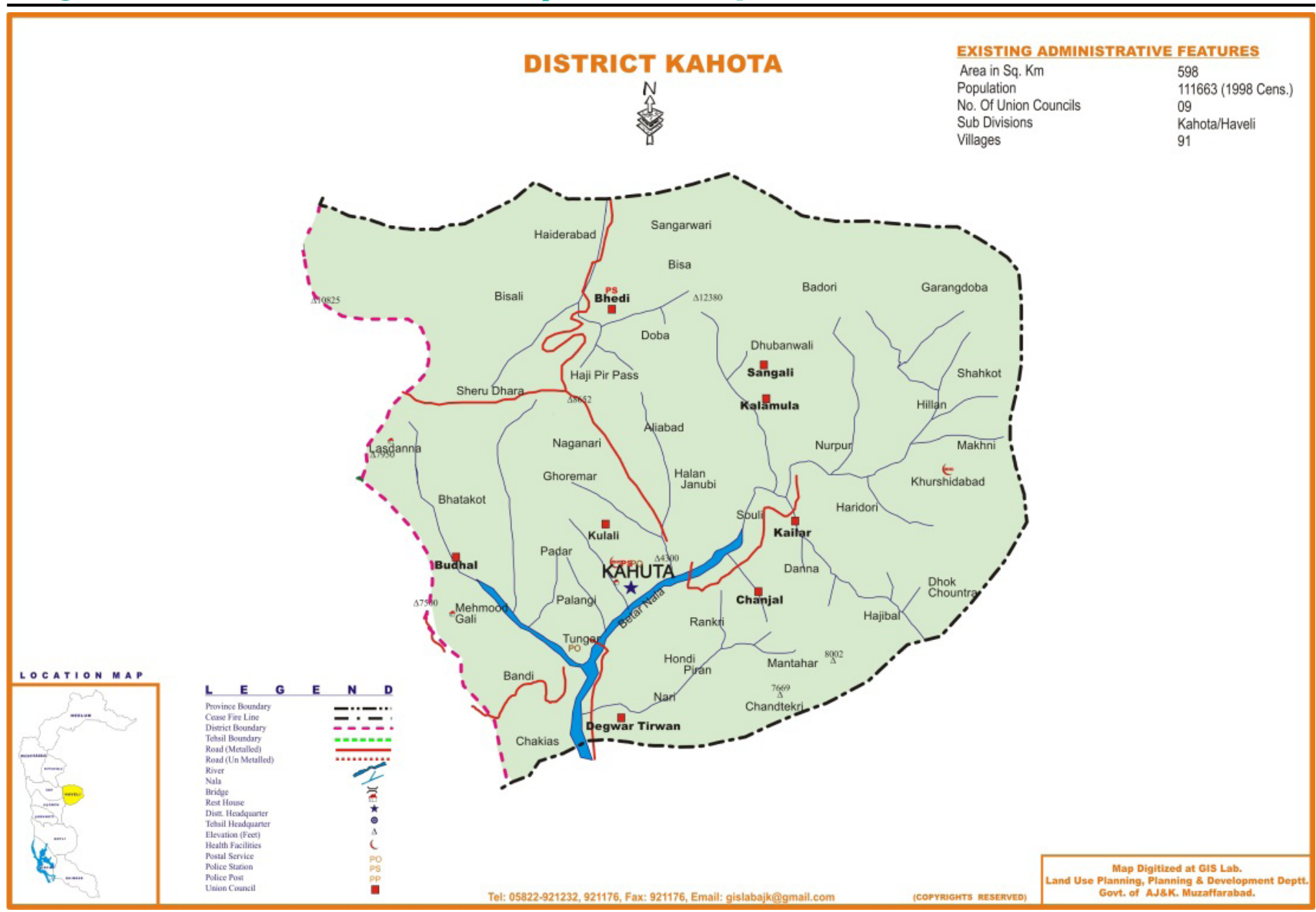

Figure 1: Map.

$\mathrm{HL}=$ Length of Head; maximum length of head in full face view excluding mandibles.

$\mathrm{HW}=$ Width of Head; maximum width of head behind eyes in full-face view.

PTL=Length of Petiole; maximum length measured in dorsal view ranging from anterior margin to posterior margin.

PTW=Width of Petiole; maximum width measured in dorsal view.

SL=Length of Scape

$\mathrm{FL}=$ Maximum Length of Femur of proleg.

\section{Indices}

CI Cephalic index: HW/HL* 100

SI Scape index: SL/HW* 100

\section{Results and Discussion}

\section{Genus Pseudoneoponera Donisthorpe, 1943}

The genus Pseudoneoponera was synonymized with Botbroponera by Wilson (1958), with Pachycondyla by Brown (1994) and ultimately placed it in the tribe Ponerini by Bolton (2003). However, based on the recent molecular phylogenetic analysis (Schmidt,
2013); Schmidt and Shattuck (2014) the genus Pseudoneoponera is recognized as separate genus and placed under the Odontomachus genus group of the tribe Ponerini.

Pesudoneoponera rufipes Jerdon, 1851 (Figure 2 A-F) Ponera rufipes Jerdon, 1851

Type locality: India: Kerala: Malabar

Type depository: T: Unknown

Morphometric data of the worker: TL $14.11 \mathrm{~mm}$, HL 3.66mm; HW 2.90mm; EL $0.53 \mathrm{~mm}$; SL $2.67 \mathrm{~mm}$; PL $1.009 \mathrm{~mm}$, PW 0.707mm; FL 1.080; PTL $1.004 \mathrm{~mm}$, PTW $0.556 \mathrm{~mm}$

Indices: CI 79.23mm; SI 92.06mm

Bionomics: Pseudoneoponera rufipes usually found in wooded habitats.

Diagnostic Characters: Body furrowed, rigid and channeled throughout; antenna 12 segmented; jaw usually finely toothed, sub-triangular; mesosoma March 2022 | Volume 35 | Issue 1 | Page 48 


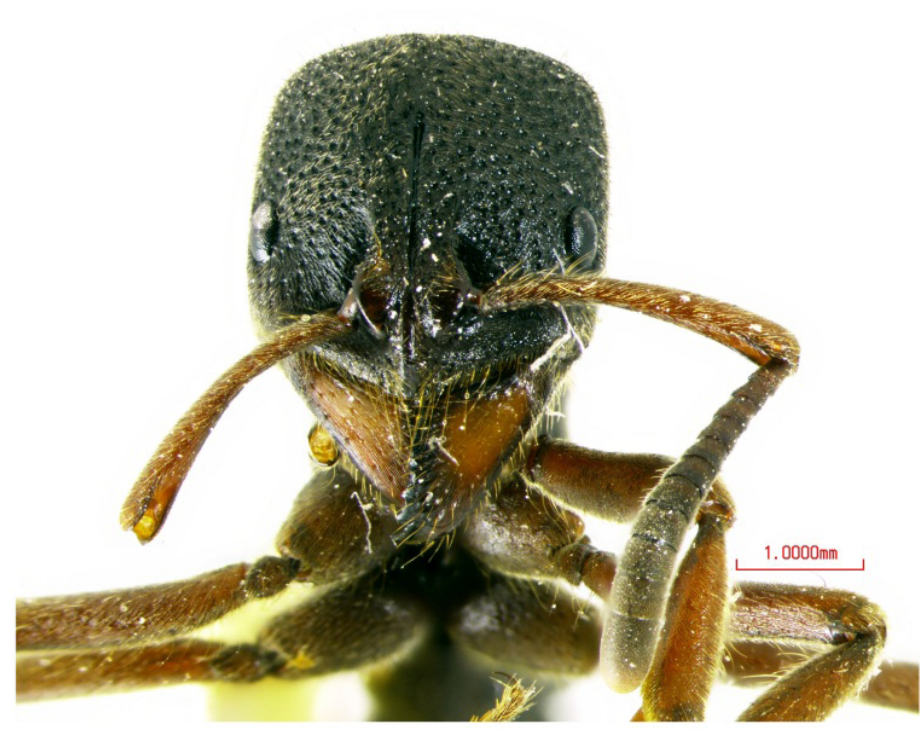

A
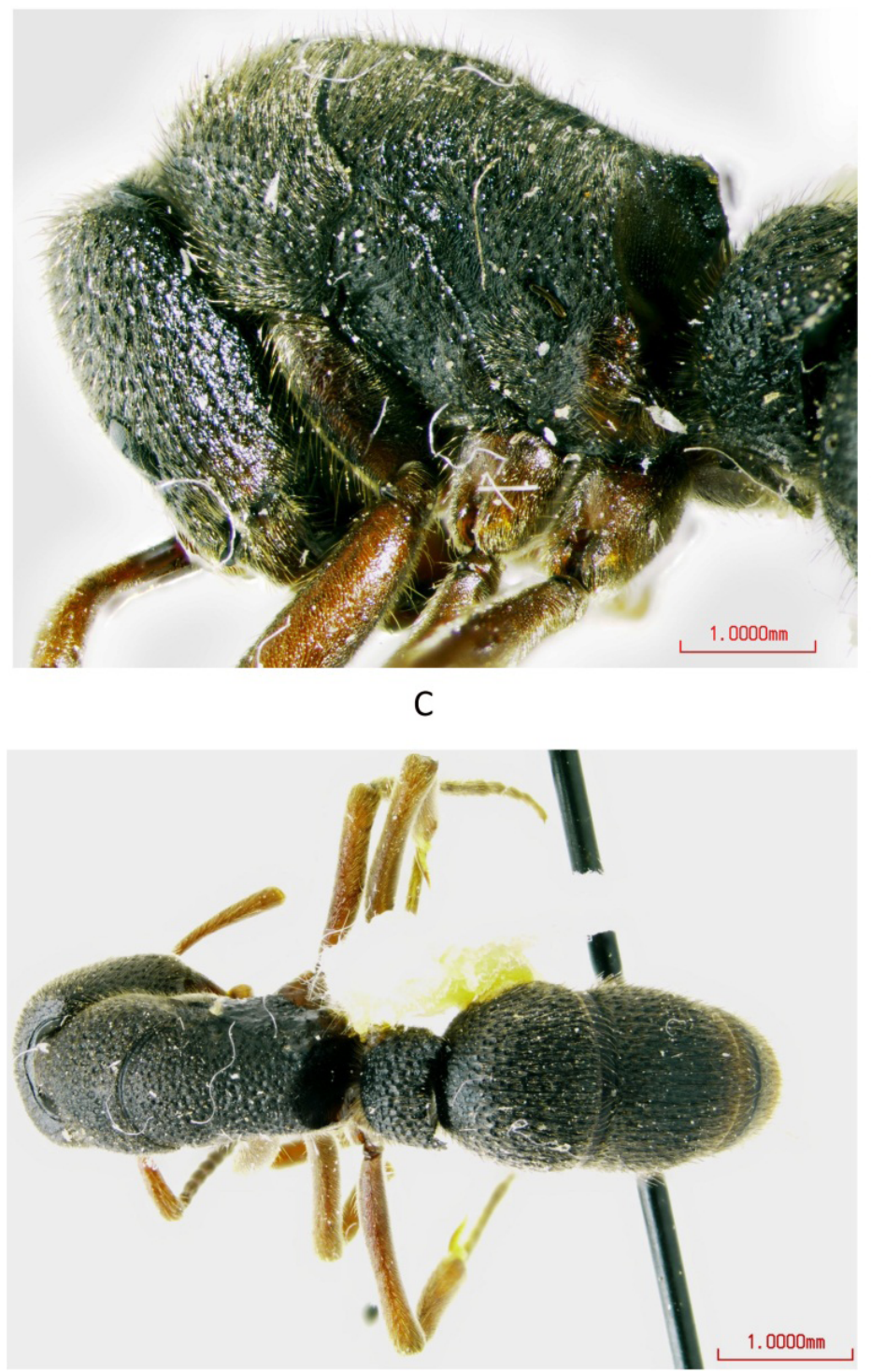

E

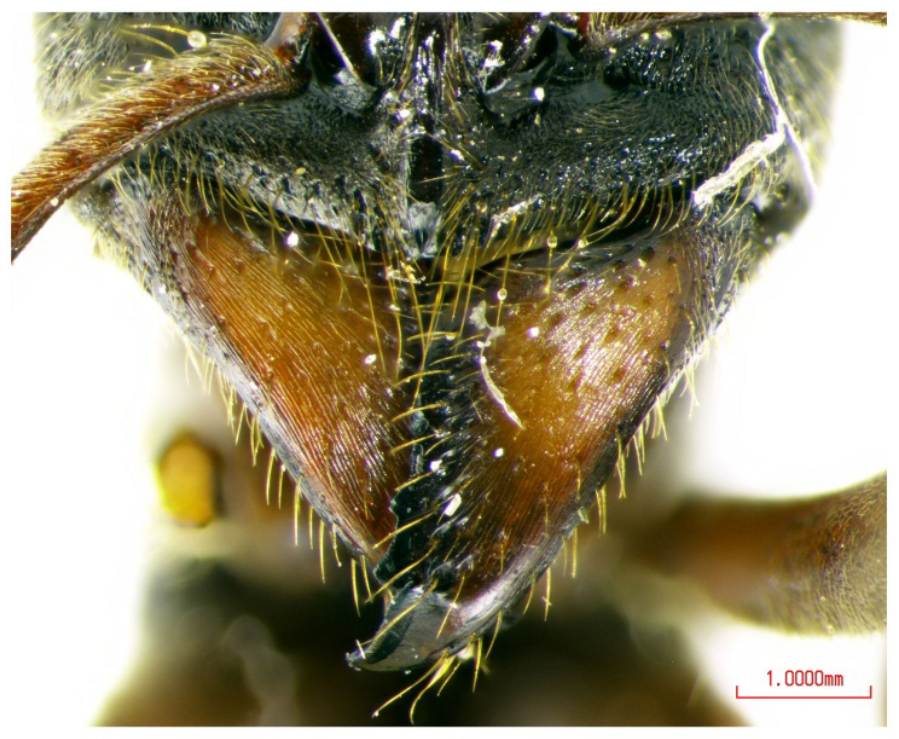

B

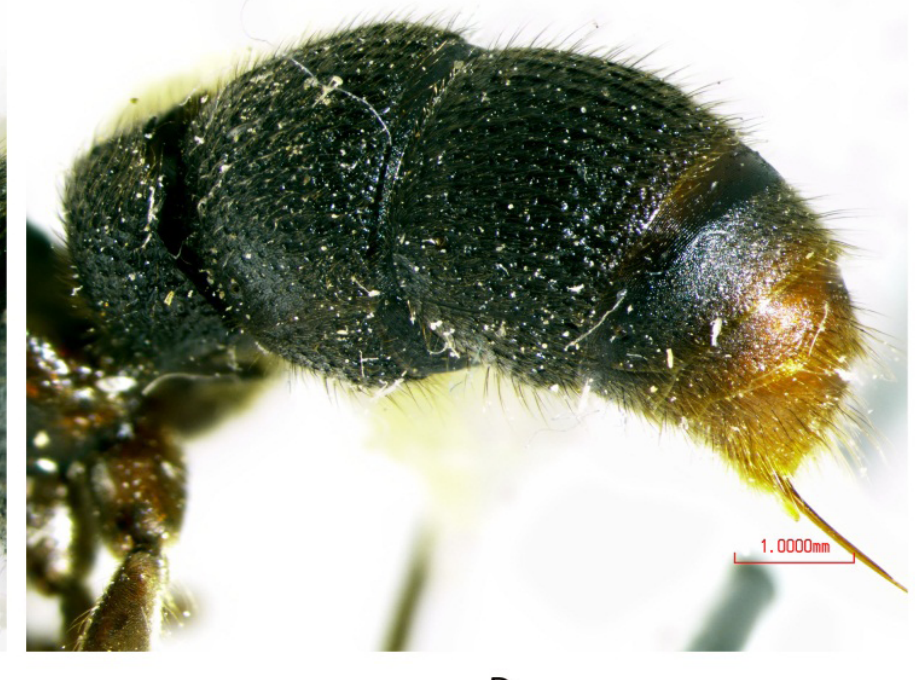

D

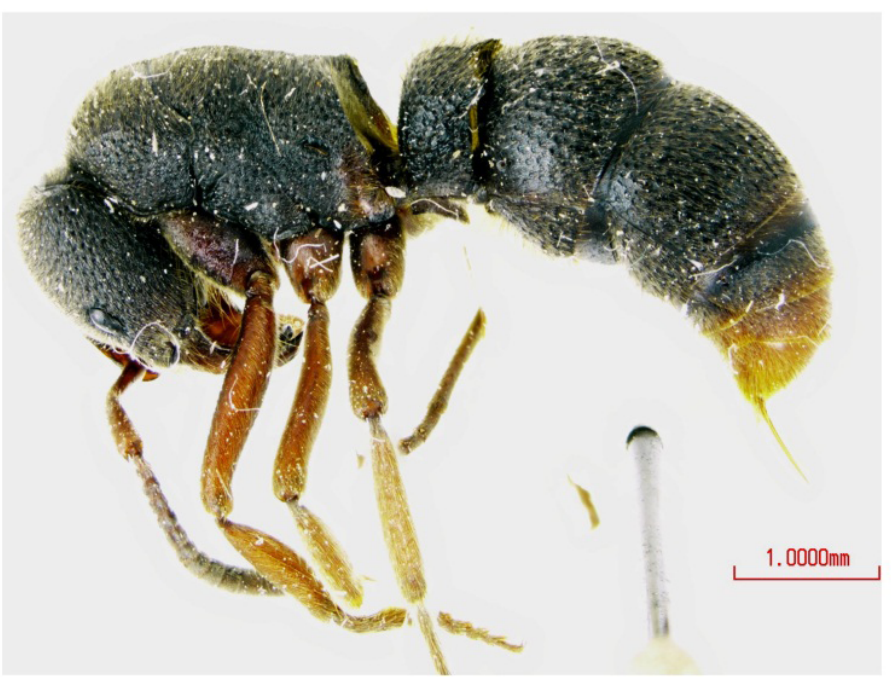

$\mathrm{F}$

Figure 2: A-F. Pseudoneoponera rufipes, sp. n., major worker; A) Head, full face view; B) Mandibles; C) Propodeum; D) Gaster, dorsal view; E) body, dorsal view; F) Body, lateral view. 
posteriorly truncate, not furrowed; metasoma with pedicle posteriorly excavated, truncate and thick; metasomal end dark rufous.

\section{Description}

Body Length: $14.11 \mathrm{~mm}$.

Body colour: Dull black in color; legs, antenna and metasomal end dark rufous.

Vestiture: Body clothed with long outstanding and short sub-decumbent dense yellow hairs.

Head: Head with dense hairs, coarsely sculptured, oblonged with convex sides; flagellum 11 segments; preoccipital carina laterally and dorsally conspicuous; frontal lobes straight, separated by longitudinal sulcus from each other; Antenna 12 segmented thick, short, without scrobe; clypeus usually with a pair of median carina, medially with anterior face sharp; clypeus with antero-median margin convex; mandibles usually sub-triangular, basal portion dorsolaterally with fovea, strongly toothed; eyes small sized and anterior.

Mesosoma: Mesosoma with dense hairs, coarsely sculptured, posteriorly truncate and not furrowed; metanotal groove absent; mesonotum with distinct suture, metapleuron separated from mesopleuron; propodeum exposed; propodeal spiracle with orifice slit like; propodeal lobe nearly absent; pronotum separated from mesonotum by promesonotal suture; front tibia with a small apicoventral spur behind large pectinate spur; apicoventral part of hind and mid tibia with small spur in front of large spur; petiole with anterior peduncle absent; petiolar node dorsally semi-circular, thick and high laterally; row of denticles present on posterodorsal margin of petiolar node.

Metasoma: Metasoma usually long with joints divisions marked strongly; hairs dense and short; metasomal segments 3 and 4 with distinct girdling construction; petiole sub rectangular; tergite 3 longitudinally striate strongly; $3^{\text {rd }}$ sternite with distinct anteroventral flange; last segments of metasoma dark rufous; sting well developed, sharp and upcurved.

Distribution: The species Pseudoneoponera rufipes is widely distributed in Oriental region: Vietnam, Thailand, Sri Lanka, Pakistan, Nepal, Laos, India and Palaearctic region: China (AntWeb, 2021). It is previously reported from Rawalpindi, Pakistan by Rasheed et al. (2019).
Material Examined: Pakistan; Azad Kashmir, Kahuta, 2 \%. $33.5896^{\circ} \mathrm{N}, 73.3886^{\circ}$ E. 14.vi.2019. Ullah, $\mathrm{N}$.

Comments: It can be identified by: Metasomal end dark rufous; metasoma with pedicle posteriorly excavated, truncate and thick; mesosoma posteriorly truncate and not furrowed; jaw usually finely toothed and sub-triangular; antenna 12 segmented. In the present study the species is reported for the first time from Kahuta, Azad Kashmir Pakistan.

\section{Conclusions and Recommendations}

The area contains rich ant fauna and very little work is done till date. As this species is the new record for $\mathrm{Ka}-$ huta Azad Kashmir, it is recommended that an extensive collection should be made in order to completely explore the ant fauna of Kahuta, Azad Kashmir.

\section{Acknowledgements}

The authors are thankful to Himender Bharti and Aijaz Ahmad Wachkoo for confirmation of species. Also Thankful to Dr. Kamran Sohail for the manuscript review and editing.

\section{Novelty Statement}

The reported the genus Pseudoneoponera Doinsthrope is new record for the study area.

\section{Author's Contribution}

Najeeb Ullah: Described the species and wrote manuscript.

Adnan Ihsan and Syed Fahad Shah: Provided literature and helped in identification of specimens.

Kamran Sohail: Supervised the overall activities and revised the manuscript.

Muhammad Sohail Khan and Said Hussain Shah: Provided technical support.

\section{Conflict of interest}

The authors have declared no conflict of interest.

\section{References}

Antweb. 2021. AntWeb. An online catalog of the ants of the world. Version 8.54.9. California Academy of Science (https://www.antweb.org). 
Bolton, B. 2011. Bolton's Catalogue and Synopsis. (https://gap.entclub.org/ Version: 1).

Bolton, B. 2021. An online catalog of the ants of the world. (https://antcat.org).

Bolton, B. 2003. Synopsis and Classification of Formicidae. Mem. Am. Entomol. Inst. 71: 370pp (page 168, Pseudoneoponera as junior synonym of Pachycondyla)

Brown, W.L. 1973. A comparison of the Hylean and Congo-West African rain forest ant faunas. pp. 161-185. In: Meggers, B. J., Ayensu, E. S., Duckworth, W. D. (eds.). Tropical forest ecosystems in Africa and South America: a comparative review.

Hölldobler, B. and E. O. Wilson. 1990. The Ants. Harvard University Press, Cambridge. https:// doi.org/10.1007/978-3-662-10306-7

Rasheed M.T., I. Bodlah, A.G. Fareen, A.A. Wachkoo, X. Huang and S.A. Akbar. 2019. A
Checklist of Ants (Hymenoptera: Formicidae)

in Pakistan. Sociobiology, 66(3): 426-439. https://doi.org/10.13102/sociobiology. v66i3.4330

Schmidt, CA. and S.O. Shattuck. 2014. The Higher Classification of the Ant Subfamily Ponerinae (Hymenoptera: Formicidae), with a Review of Ponerine Ecology and Behavior. Zootaxa. 3817 (1): 001-242. https://doi.org/10.11646/ zootaxa.3817.1.1

Ward, P.S. 2007. Phylogeny, classification, and species-level taxonomys of ants (Hymenoptera: Formicidae). Zootaxa., 1668: 54. https://doi. org/10.11646/zootaxa.1668.1.26

Wilson, E.O. 1958. Studies on the ant fauna of Melanesia III. Rhytidoponera in western Melanesia and the Moluccas. IV. The tribe Ponerini. Bull. Museum of Comp. Zool., 119: 303-371. 